\title{
Rare site giant cell tumors: report of two cases on phalanges of the finger and review of literature
}

\author{
Kabul C. Saikia · S. K. Bhuyan · S. Goswami • \\ A. Bora
}

Received: 6 June 2008/ Accepted: 20 January 2009/Published online: 29 September 2009

(C) Springer-Verlag 2009

\begin{abstract}
Giant cell tumor (GCT) of bone arising from a phalanx of a finger is extremely rare. We report two cases of GCT arising from a phalanx of a finger. One case presented with recurrence following the amputation of the left ring finger (performed elsewhere). He was treated successfully with ray amputation. The other case was treated primarily by intralesional curettage and autogenous bone graft. At their most recent follow-ups (80 and 24 months, respectively), both were recurrence free and had returned to their previous occupational and recreational activities.
\end{abstract}

Keywords GCT $\cdot$ Phalanx $\cdot$ Recurrent

\section{Introduction}

Giant cell tumor (GCT) of a phalanx of a finger is extremely rare. Only $2 \%$ of all reported GCTs are found in the hand [1]. The metaphyseal region of the metacarpals and phalanges has been found to be the common site of GCTs in most of the reported cases [2-4]. Though GCT is not a sarcoma, its relatively high recurrence rate [5] coupled with local aggressiveness after simple curettage often requires extensive en bloc excision. The recurrence of GCT of hand is higher than for other locations. Local recurrence following curettage and bone grafting has been reported to

K. C. Saikia · S. K. Bhuyan · S. Goswami · A. Bora

Department of Orthopaedic Surgery,

Gauhati Medical College and Hospital, Guwahati,

Assam 781032, India

K. C. Saikia $(\bowtie)$

Rajghar Link Road, Anil Nagar, Bye lane-5, House No-7,

Guwahati, Assam 781007, India

e-mail: drkabul_saikia@yahoo.com be as high as $90 \%[1,4,6,7]$. Wide resection and reconstruction with structural bone grafting is also reported to have a high local recurrence rate [6]. Multiple procedures like excision (local or wide), ray amputation, and amputation are used to eradicate the disease completely. Even with single- or double-ray resection for primary or recurrent tumors, local tumor control may not be absolute.

Here, we report two cases of GCT on phalanges of the finger, noting the rarity of a lesion at this site.

\section{Case report}

\section{Case 1}

A 50 year old man presented in June 2001 with an ulcerated swelling of two months duration over the amputated left ring finger. Careful history taking and a review of his records led to a diagnosis of GCT of the proximal phalanx of the left ring finger, where amputation of the proximal phalanx through its base had been performed elsewhere one year earlier. He gave an associated history of traumatic amputation of the pulp of the left index finger in his childhood. A review of previous radiographs showed an expansile lytic lesion at the proximal phalanx involving only the proximal metaphysis and diaphysis, sparing the distal end with an intact articular surface. There was huge soft tissue swelling with gross erosion of the cortex. The metacarpophalangeal joint appeared normal. A review of the previous histological picture (Fig. 1) showed sheets of mononuclear stromal cells with numerous osteoclastic giant cells and osteoid tissue formation in certain areas. He was asymptomatic for one year after the surgery until he noticed a progressive swelling on the amputated stump. The surgical scar was subsequently broken after a month, 




Fig. 1 Histopathological picture showing typical features of the giant cell tumor $(40 \times$ magnification $)$

leading to ulcer formation, and exposing the underlying tumor mass.

On examination, an ulcerative swelling about $2 \mathrm{~cm} \times$ $3 \mathrm{~cm}$ in size involving all of the amputated stump was seen (Fig. 2a). The swelling was globular in shape, firm in consistency, and tender. The margin of the ulcer was not everted and was fixed to the tumor mass. The overlying skin was found to be fixed and markedly stretched. Regional lymph nodes were not palpable.

A radiograph revealed partial amputation of the proximal phalanx through the proximal one-third, with an expansile lesion in the remaining part involving the articular surface that was associated with soft tissue swelling (Fig. 2b). CT scan clearly demonstrated an irregular expansile lytic lesion with cortical erosion (Fig. 2c). Evidence of new bone formation was prominent. A radiograph of the chest was normal. There were no signs of the disease elsewhere in the body. Results of laboratory studies were within normal limits.

Ray resection of the amputated ring finger was performed under general anesthesia. Resected tumor tissue (Fig. 3) was found to involve the entire base of the proximal phalanx, including the articular cartilage, with areas of new bone formation. Histopathological examination reconfirmed that it was a giant cell tumor. The patient had an uneventful recovery.

At his most recent follow-up (80 months), neither clinical nor radiological evidence of local recurrence was seen. He was able to perform normal activities of daily life. There was no limitation on the strength or motion of the uninvolved digits or wrist.

\section{Case 2}

A 26 year old female presented with a painless swelling of the left little finger of six months duration without any history of trauma or fever.


Fig. 2 a Amputation stump with ulcer at the tip. b Radiograph showing partial amputation of the proximal phalanx with expansile lesion involving the articular surface. c CT scan showing the irregular expansile lytic lesion with cortical erosion

Examination revealed a fusiform swelling in the middle phalanx of the little finger (Fig. 4). The overlying skin was stretched and pigmented without adherence to the underlying mass. The adjacent joints had normal ranges of movement. Regional lymph nodes were not palpable. Serum biochemistry was within normal limits. Radiographs demonstrated an expansile lytic lesion involving the entire 




Fig. 3 Resected tumor mass extending up to the joint



Fig. 4 Clinical photograph showing fusiform swelling of the little finger

phalanx with a cortical break (Fig. 5a). The articular margins were found to be intact. CT scan clearly demonstrated a cortical break (Fig. 5b). Radiograph of the chest was normal. FNAC revealed multinucleated giant cells with stromal cells in the background.

Under general anesthesia, curettage of the lesion was performed with cancellous bone grafting from the iliac crest. The recovery was uneventful. Histology confirmed the diagnosis of a GCT, demonstrating osteoclastic giant cells admixed with stromal cells.

The patient is undergoing regular check-ups for 24 months and has not shown any evidence of local recurrence clinically or radiologically (Fig. 5c). Her grip strength is normal, with good functional recovery.

Informed consent was obtained from both of the patients to publish their clinical cases.

\section{Discussion}

GCT of the hand is rare and seems to be different from conventional GCT, which occurs at other sites in the skeleton. GCTs recur more rapidly in the hand than they do in other locations. It is even rarer to encounter a GCT arising from the phalanges. Of the more than 2,400 skeletal GCTs reported in the literature, less than 50 were found to involve the phalanges of the hand [7, 8]. Coley et al. [9] reported only two cases of GCT arising from the phalanges in their series of 108 cases. Goldenberg et al., in their analysis of 218 cases of GCT, reported six cases involving the phalanges [10]. In another two large series of 568 and 327 cases of GCT, authors found only four and one cases of phalangeal involvement, respectively [11, 12]. Yasudal et al. [13] reported a multicentric giant cell tumor of the hand involving a finger and the wrist. Benign metastazing giant cell tumor of the hand has also been reported [14]. In our series of 124 skeletal GCTs, we could find only two cases involving the phalanges.

Giant cell tumors of the hand have been treated with curettage and cancellous bone grafting, wide resection, and structural bone grafting or ray amputation $[1,4,6,7$, 15]. High local recurrence rates have been reported with these treatment modalities [1, 4, 6, 7]. Daniel et al. [16] reported a GCT of the middle phalanx treated with curettage and bone grafting, which recurred at 9 months and was successfully treated by excision and allograft replacement. Wittig et al. [17] reported three cases of phalangeal GCT treated with curettage, cryosurgery and cementation. Resection-iliac graft and double arthrodesis for GCT of the proximal phalanx of the thumb has also been reported [18].

Our patient (case no. 2) with curettage and iliac bone grafting recovered uneventfully. To avoid stiffness of fingers and tendon adhesion, we started active finger rehabilitation measures as early as the second week. The patient was still disease free at the most recent follow-up, and was performing normal activities with a good grip strength.

Most local recurrences of GCT cases of the hand are reported to occur within one year of primary surgery $[1,6]$. Patel et al. [7] treated three cases of GCT of the hand with curettage and bone grafting, two of which had local recurrence and required ray resection. Our patient (case no. 1) presented with local recurrence one year after primary surgery elsewhere, but has been disease free for more than 80 months following ray amputation of the amputated ring finger. Averill et al. [1] reported one of the largest series of GCT of the hand, consisting of 28 lesions (14 in the phalanges) in 21 patients. Sixteen of the cases had local recurrence. Two of the six cases of finger phalangeal involvement reported in Goldenberg's series developed local recurrence [10]. Table 1 shows the reported local 


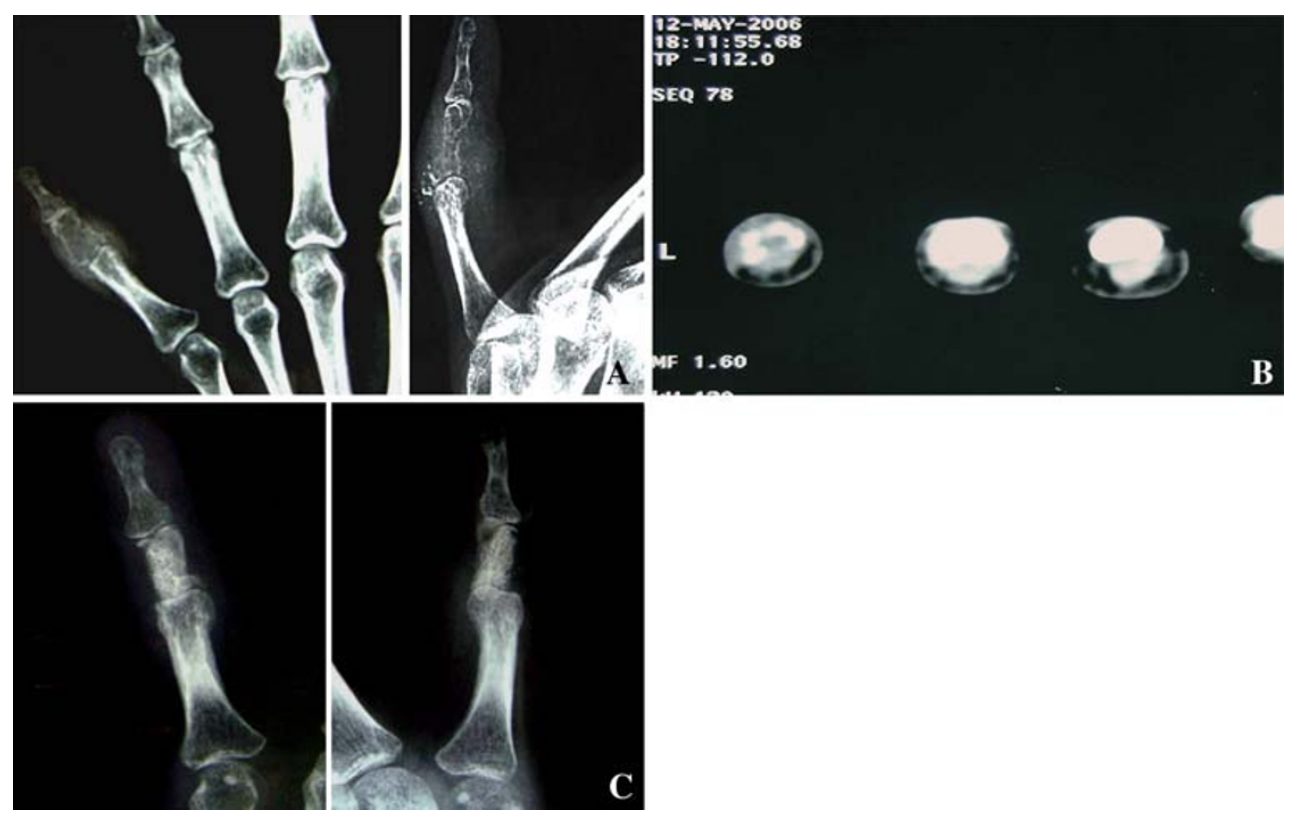

Fig. 5 a Radiograph (AP, lateral) reveals an expansile lytic lesion with cortical break. b CT scan of the middle phalanx showing marked osteolysis. c Postoperative radiograph (AP, oblique) at 14 months showing incorporation of the cancellous graft

Table 1 Reported local recurrence after curettage, resection and amputation for GCT of the hand

\begin{tabular}{|c|c|c|c|c|c|c|}
\hline \multirow[t]{2}{*}{ Sl No. } & \multirow[t]{2}{*}{ Authors } & \multirow[t]{2}{*}{ No. of cases } & \multicolumn{2}{|c|}{ Curettage \pm bone graft } & \multicolumn{2}{|c|}{ Resection or ray amputation } \\
\hline & & & Nos. & Local recurrence & Nos. & Local recurrence \\
\hline 1. & Goldenberg [10] & 6 & 1 & 1 & 5 & 1 \\
\hline 2. & Averill et al. [1] & 28 & 15 & 13 & 7 & 3 \\
\hline 3. & Wold et al. [4] & 34 & 29 & 20 & 9 & 1 \\
\hline 4. & Patel et al. [7] & 5 & 3 & 2 & 2 & 0 \\
\hline 5. & Athanasian et al. [6] & 14 & 14 & 11 & 14 & 5 \\
\hline 6. & Daniel et al. [16] & 1 & 1 & 1 & - & - \\
\hline \multirow[t]{2}{*}{7.} & This study & 2 & 1 & - & 1 & - \\
\hline & & & 64 & $48(75 \%)$ & 38 & $9(24 \%)$ \\
\hline
\end{tabular}

recurrence rates of GCT of the hand following curettage, resection and amputation.

Most of the GCT cases with recurrent tumors require ray amputation to prevent recurrence. There are reports of success with ray resection or amputation at the cost of the loss of a functional finger [7, 15]. We chose ray resection of the amputated ring finger with the aim of preventing recurrence. The recurrent tumor in our patient expanded eccentrically, leading to breakage of the surgical scar and ulcer formation. Contrary to malignant ulcers, the margin of the ulcer was not everted and did not bleed on touch. Histology of the lesion also revealed osteoid formation. Kumar and Tuli [19] and Dahlin et al. [11] reported similar histological findings in their series. Following ray resection of the ring finger, there was no functional loss of the hand in our patient. The patient was satisfied with a cosmetically improved hand.
In view of the comparative rarity of a tumor arising from the phalanges of the finger, the present two cases are considered worth reporting.

Conflict of interest statement The authors declare that they have no conflict of interest related to the publication of this manuscript.

\section{References}

1. Averill RM, Smith RJ, Campbell CJ (1980) Giant cell tumours of the bones of the hand. J Hand Surg 5:39-50

2. Feldman F (1987) Primary bone tumours of the hand and carpus. Hand Clin 3:269-289

3. Dahlin DC (1987) Giant cell bearing lesion of the bone of the hands. Hand Clin 3:291-297

4. Wold LE, Swee RG (1984) Giant cell tumour of small bones of the hands and feet. Semin Diagn Pathol 1:173-184 
5. Eckardt JJ, Grogan TJ (1986) Giant cell tumour of bone. Clin Orthop 204:45-58

6. Athanasian EA, Wold LE, Amadio PC (1997) Giant cell tumour of the bones of the hand. J Hand Surg 22A:91-98

7. Patel MR, Desai SS, Gordon SL et al (1987) Management of skeletal giant cell tumour of the phalanges of the hand. J Hand Surg 12A:70-77

8. Bloodgood JC (1919) Bone tumours central (medullary) giant cell tumour (sarcoma) of lower end of ulna, with evidence that complete destruction of the bony shell or perforation of the bony shell is not a sign of increased malignancy. Ars Surg 69:345-359

9. Coley BL, Higisibotham NL, Koguse T (1958) Giant cell tumour of bone. Am J Surg 96:479-491

10. Goldenberg R, Campbell C, Bofiglio M (1970) Giant cell tumour: an analysis of 218 cases. J Bone Joint Surg 52A:619-664

11. Dahlin DC (1996) Dahlins bone tumours: general aspects and data of 11,087 cases, 5th edn. Lippincott-Raven, Philadelphia

12. Campanacci M, Baldioni N, Boriami S, Sudonese A (1987) Giant cell tumour of the bone. J Bone Joint Surg 69A:106-113
13. Yasudal T, Kanamoril M, Ishizawa S et al (2008) Multcentric diffuse type giant cell tumour of the hand. Mod Rheumatol 18:67-71

14. Lopez-Barea F, Rodriguez-Peralto JL, Garcia-Giron J, GuemesGordo F (1992) Benign metastizing giant cell tumour of the hand. Report of a case and review of the literature. Clin Orthop Relat Res 274:270-274

15. Slesarencko YA, Sampson SP, Gould ES (2005) Giant cell tumour of the distal phalanx of the hand. Hand Surg 10(23):289-291

16. Daniel JN, Eglseder WA, Sydney SV (2000) Giant cell tumour of middle phalanx. Orthopaedics 23(10):1097-1099

17. Wittig JC, Simpson BM, Bickels J et al (2001) Giant cell tumour of the hand: superior results with curettage, cryosurgery, and cementation. J Hand Surg 26(3):546-555

18. Fnini S, Labsaili N, Messoudi A, Largab A (2008) Giant cell tumour of the thumb proximal phalanx: resection iliac graft and double arthrodesis. Chir Main 27(1):54-7

19. Kumar S, Tuli SM (1971) Giant cell tumour of the middle phalanx of the left fifth finger. Int Surg 55(4):288-292 